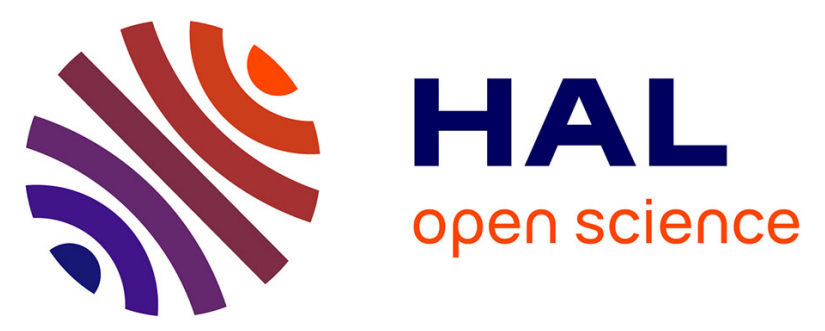

\title{
Ligand effects in gold-carbonyl complexes: evaluation of the bond dissociation energies using blackbody infrared radiative dissociation
}

David Gatineau, Héloïse Dossmann, Hervé Clavier, Antony Memboeuf, László Drahos, Yves Gimbert, Denis Lesage

\section{To cite this version:}

David Gatineau, Héloïse Dossmann, Hervé Clavier, Antony Memboeuf, László Drahos, et al.. Ligand effects in gold-carbonyl complexes: evaluation of the bond dissociation energies using blackbody infrared radiative dissociation. International Journal of Mass Spectrometry, In press, 10.1016/j.ijms.2021.116545 . hal-03142381

\section{HAL Id: hal-03142381 \\ https://hal.science/hal-03142381}

Submitted on 16 Feb 2021

HAL is a multi-disciplinary open access archive for the deposit and dissemination of scientific research documents, whether they are published or not. The documents may come from teaching and research institutions in France or abroad, or from public or private research centers.
L'archive ouverte pluridisciplinaire HAL, est destinée au dépôt et à la diffusion de documents scientifiques de niveau recherche, publiés ou non, émanant des établissements d'enseignement et de recherche français ou étrangers, des laboratoires publics ou privés. 


\section{Ligand effects in gold-carbonyl complexes: evaluation of the bond dissociation energies using blackbody infrared radiative dissociation}

David Gatineau, ${ }^{1,2}$ Héloïse Dossmann, ${ }^{2}$ Hervé Clavier, ${ }^{3}$ Antony Memboeuf, ${ }^{4}$ László Drahos, ${ }^{5}$ Yves Gimbert, ${ }^{1,2}$ Denis Lesage ${ }^{2 *}$

1. Univ. Grenoble Alpes, CNRS, DCM, 38000 Grenoble, France

2. Sorbonne Université, CNRS, Institut Parisien de Chimie Moléculaire, IPCM, F-75005 Paris, France

3. Aix Marseille Univ, CNRS, Centrale Marseille, iSm2, Marseille, France

4. Université de Bretagne Occidentale, CNRS, CEMCA (UMR 6521), 29238 Brest, France

5. MS Proteomics Research Group, Research Centre for Natural Sciences, Magyar Tudósok körútja 2, H-1117, Budapest, Hungary

ABSTRACT. In a previous work, the ability of gold-carbonyl bond dissociation energies (BDEs) to describe ligand effects in gold(I) complexes was probed using collision-induced dissociation measurements. Despite the large experimental error of the technique, results agreed with theoretical description of these effects. We propose here another experimental approach to evaluate the BDEs of $[\mathrm{LAu}-\mathrm{CO}]^{+}$complexes, by using Blackbody Infrared Radiative Dissociation (BIRD) method which is able to provide absolute energetic measurements. To this aim, the dissociation of 8 gold-carbonyl complexes was studied with this approach to obtain their Arrhenius activation energies. Because these complexes do not reach the rapid energy exchange (REX) limit conditions, critical energies of these dissociations were then determined using the kinetic data and an equilibrium truncated thermal (ETT) internal energy distribution model implemented in the RRKM-QET MassKinetics software. To validate our approach, the known critical energies of proton-bound amino acid dimers were first reinvestigated using this model. The results are in excellent agreement with those reported in the literature. This indicates that the assumptions of this simple model are reasonable and allow the determination of 
accurate dissociation energies. For $[\mathrm{LAu}-\mathrm{CO}]^{+}$complexes, even though a shift (from 0.18 to $0.26 \mathrm{eV}$ ) is observed between binding energies obtained and calculated values, a linear tendency between these two sets of data is still obtained. These results validate the use of BIRD in combination with equilibrium truncated thermal internal energy distributions model to obtain dissociation energies for relatively small ions. It is also shown herein that the measure of the gold-carbonyl bond dissociation energies is a good descriptor of ligand effects in gold(I) complexes that may be reliably evaluated using the BIRD technique.

Keywords: BIRD, FT-ICR, RRKM modeling, BDE, Ion-molecule reactions

*Corresponding author.

Email address: denis.lesage@,sorbonne-universite.fr (D. Lesage) 


\section{Introduction}

Homogeneous gold catalysis has grown spectacularly during the past two decades [1]. It is frequently applied in various areas such as cyclization processes [2], but also in total synthesis [3]. In cyclization transformations, the typical procedure involves bifunctional substrates bearing an unsaturation capable of electrophilic activation by the gold catalyst and a judiciously positioned internal nucleophile. This mode of reactivity involves catalytic cycles wherein gold maintains a $+\mathrm{I}$ oxidation state. A fine tuning of the steric and electronic properties of ligands in the coordination sphere of gold(I) plays a key role in the catalytic efficiency [4]. In a recent study, we have determined the experimental critical energies $\left(\mathrm{E}_{0}\right)$ related to the loss of a $\mathrm{CO}$ moiety of $16[\mathrm{LAu}-\mathrm{CO}]^{+}$complexes and established a relation between Au-CO bond strength and electronic properties of the metal center [5]. These measurements were performed by collision-induced dissociation (CID) using a triple quadrupole working at high collision pressure. The energy deposited on each complex before fragmentation was defined by a characteristic temperature $T_{\text {char }}[6,7]$. This characteristic temperature model, introduced by DePauw and Vékey [8,9], considers that the collisional activation process is fast compared to the fragmentation process and that these two processes take place consecutively. Moreover, the deactivation phenomenon is not considered for this simple model. Such characteristic temperature model suits well for the description of fast activation processes occurring in Atmospheric Pressure Ionization (API) sources via multiple collisions. It was previously conveniently used to describe properties of ions formed by many sources such as: electrospray ionization (ESI) or (nano)-electrospray ionization ((nano)-ESI) [9-14], Atmospheric Pressure Chemical Ionization (APCI) [15], active capillary Dielectric Barrier Discharge Ionization (DBDI) and Direct Analysis in Real-Time Mass Spectrometry (DART) [16], Venturi-Assisted Electrospray Ionization and Venturi-Assisted Array of Micromachined UltraSonic Electrosprays Ionization (AMUSE) [17] or various laser desorption techniques [18-20]. 
Multiple collisions taking place in a triple quadrupole collision cell or in the higher-energy collisional (HCD) cell of an orbitrap spectrometer have also been described using $T_{\text {char }}$ when operating under high pressure conditions [21,22].

Thus, in this previous paper [5], after calibration of this characteristic temperature, which depends on the size of the system and on the collision voltage, the critical energies $E_{0}$ of the 16 studied complexes dissociation could be extracted from a RRKM/QET (Rice-RamspergerKassel-Marcus/Quasi-Equilibrium Theory) $[23,24]$ modeling of the sigmoidal curves from surviving ions. With the original approach developed in this previous work, we were able to compare fragmentation energies for ions of very different sizes. This feature remains a challenge in mass spectrometry. For the studied ions, the internal number of degrees of freedom (DoF), in the statistical rigid rotor approximation, ranges from 42 to 330 . The energy deposited on an ion indeed depends on i) the number of effective collisions (depending on the size of the system) and ii) the amount of energy transferred for each collision. This energy is related to the mass of the ion relative to that of the target gas and to the kinetic energy of the precursor ion which varies during its journey through the collision chamber. Furthermore, the size of the molecular system has a major effect on the kinetic shift (KS, amount of additional energy above the critical energy required by an ion to decompose within the time frame of the MS experiment) [25]. For these reasons, we were not able to provide absolute values of $E_{0}$ in our previous CIDstudy, but rather relative semi-empirical data since the calculated values of the BDEs (bond dissociation energies, obtained at the PBE0-D3BJ/def2-TZVP level of theory) were required to calibrate an average energy deposited on each complex [5].

In the present study, we go a step further and present absolute measurements of $E_{0} s$ related to the decomposition of $[\mathrm{LAu}-\mathrm{CO}]^{+}$complexes. To this end, measurements were performed using the Blackbody Infrared Radiative Dissociation (BIRD) technique [26-28]. In the literature, this method has often been used for the determination of thermodynamic parameters especially in 
the case of rather weak interactions for large molecules but may be also used for molecules of various sizes [28]. Briefly, the studied ions are trapped at the center of an ICR cell (Ion Cyclotron Resonance) under ultra-low-pressure conditions. With these conditions, radiative energy transfer, which results from the heating of the ICR cell housing, dominates over collisional energy exchange. Ions can both absorb and emit IR radiation or decompose. For ions at thermal equilibrium at temperature $T$, the unimolecular dissociation reaction follows a firstorder rate law (Eq. (1)):

$$
\ln S Y=-k t
$$

where $k$ is the dissociation rate constant and $t$, the reaction time in the ICR cell (time left for decomposition). SY stands for survival yield and corresponds to the fraction of the precursor ions that did not decompose. It can be defined as (Eq. (2)):

$$
S Y=I_{p} /\left(I_{p}+\sum I_{f}\right)
$$

where $I_{p}$ is the abundance of precursor ions, $\sum I_{f}$, the sum of the abundances of fragment ions. By modifying the residence time of ions inside the ICR cell at different temperatures $T$, the constant $k$ may be obtained. Subsequently, plot of $\ln k$ versus $1 / T$ allows to obtain the experimental activation energy $\left(E_{a}\right)$ and pre-exponential factor $(A)$ parameters from Arrhenius law (Eq. (3)):

$$
\ln k=\ln A-E_{a} / R T
$$

This ideal case, where ions are at thermal equilibrium is only reached for large ions. For a large number of infrared active modes, the rates of absorption and emission of photons may indeed be much faster than the rate of dissociation. These conditions are termed rapid energy exchange (REX) limit [28-30]. REX conditions may be fulfilled depending mainly on the ion size, but also on the thermochemical parameters related to the reaction as well as the temperature of the trapping cell. The advantage of working at the REX limit is that Arrhenius parameters are 
directly obtained from Arrhenius plots without complex modeling. Besides the REX limit, two other regimes may be defined for small and intermediate size molecules [28].

In the present study, the limited size of the complexes of interest implied that the REX limit was not necessarily reached. The RRKM-QET MassKinetics software (version 1.17), developed by K. Vékey and L. Drahos [31], was used in this project and modified in order to introduce equilibrium truncated thermal (ETT) internal energy distributions into the model. In the following, this approach, much simpler than the Master Equation Modeling (MEM) approach proposed by Price and Williams [29], is first validated using literature data processed by MEM. Then, critical energy values $\left(E_{0}\right)$ obtained for 8 studied $\mathrm{Au}(\mathrm{I})$ complexes are presented and discussed. These data are also compared to our published calculated BDEs [5]. Note that for large systems under REX conditions, the BIRD technique gives access to activation energy $\left(E_{a}\right)$ values whereas RRKM-QET modeling provides critical energy $\left(E_{0}\right)$ values (at $0 \mathrm{~K}$ ), which will be directly compared to our previously published calculated BDEs.

\section{Experimental Procedures}

\subsection{Mass spectrometry experiments}

[LAuCl] complexes $\left(\mathrm{L}=t \mathrm{Bu}_{3} \mathrm{P}, \mathrm{Cy}_{3} \mathrm{P}, \mathrm{Ph}_{3} \mathrm{P}\right)$ and $\mathrm{AgOTf}$ were purchased from Sigma-Aldrich or synthesized by addition of 1 equivalent of $\mathrm{L}\left[\mathrm{L}=(p \mathrm{OMePh})_{3} \mathrm{P},\left(p \mathrm{CF}_{3} \mathrm{Ph}\right)_{3} \mathrm{P},(\mathrm{biPh} t \mathrm{Bu})_{3} \mathrm{P}\right.$, $\left.\left(t \mathrm{Bu}_{2} \mathrm{PhO}\right)_{3} \mathrm{P}\right]$ to a $\mathrm{CH}_{2} \mathrm{Cl}_{2}$ solution of $\left(\mathrm{SMe}_{2}\right) \mathrm{AuCl}$. Solutions of [LAuCl] $(1 \mathrm{mg} / \mathrm{mL}, \mathrm{MeOH})$ and $\operatorname{AgOTf}\left(1 \mathrm{mg} / \mathrm{mL}, \mathrm{CH}_{2} \mathrm{Cl}_{2}\right)$ were freshly prepared and mixed before injection $(1: 1 \mathrm{v}: \mathrm{v}$ in $\mathrm{MeOH}$ ) with a $1 \mu \mathrm{g} / \mathrm{mL}$ concentration. $[\mathrm{LAu}]^{+}$ions were formed in the Apollo II electrospray ionization source of a homemade modified 7 Tesla hybrid quadrupole-FT-ICR mass spectrometer (Apex-Qe, Bruker Daltonics, Billerica, USA). The temperature of the source was set at $250{ }^{\circ} \mathrm{C}$, the ESI voltage at $4500 \mathrm{~V}$, the capillary exit at $300 \mathrm{~V}$, the skimmer I at $70 \mathrm{~V}$, the skimmer II at $8 \mathrm{~V}$ and $\mathrm{N}_{2}$ was used as nebulizing gas. 
$[\mathrm{LAu}-\mathrm{CO}]^{+}$complexes 1-8 were formed in the hexapolar collision cell from the reaction of $[\mathrm{LAu}]^{+}$ions with carbon monoxide that was introduced at a pressure of $1 \cdot 10^{-6}$ mbar in addition to a nitrogen pressure of $5 \cdot 10^{-6}$ mbar. The polarization of the collision cell was set at $0 \mathrm{~V}$ and the reaction time was set equal to $1 \mathrm{~s}$. After isolation in the FT-ICR cell, the $[\mathrm{LAu}-\mathrm{CO}]^{+}$ions were submitted to BIRD experiments under ultra-low-pressure conditions (around $10^{-10} \mathrm{mbar}$ for our experiments). Heating of the FT-ICR cell was performed by installing a resistive heating metallic "ribbon" external to the vacuum system that covers the entire vicinity of the cell; applying a variable voltage to the metallic ribbon allows temperature control. A temperature probe was placed between the metallic ribbon and the cell housing. As previously described, the dissociation of sodiated dimer of leucine enkephalin was used to check the accuracy of the cell temperature [32]. All mass spectra were acquired using XMASS (version 6.1, Bruker Daltonics) in broadband mode. The number of data points was set at $128 \mathrm{~K}$ and the time allowed for the unimolecular dissociation reaction to occur was varied by changing the "pumping delay" (without gas introduction, this corresponds to the period of time that ions are trapped in the cell).

\subsection{Theoretical data}

Theoretical data obtained at the PBE0-D3/def2-TZVP level of theory using Gaussian09 D01 [33] and those presented in our previous work were used for the simulations [5]. Vibrational frequencies (assuming harmonic oscillator and rigid rotor modes without considering anharmonicity) were calculated for the fundamental states. As usual, harmonic frequencies are given in $\mathrm{cm}^{-1}$ instead of $\mathrm{Hz}$. The transition-state frequency sets were constructed from those of the reactant by removing a single frequency corresponding to the reaction coordinate (here, the $\mathrm{Au}-\mathrm{CO}$ bond stretch) and by lowering up 5 frequency values [29, 34-36]. These frequencies correspond to the 5 main frequencies involved in the fragmentation process (typically some frequencies below $500 \mathrm{~cm}^{-1}$ ). To this end, we first followed their variation in the course of the 
Au-C bond elongation. Each $0.1 \AA$ steps, a frequency calculation was performed on the corresponding optimized geometry. The TS was defined at the step where the lowest values for the 5 frequencies were obtained. These minima were observed at $5 \AA$ elongation for the complex 3-Cy with L = Cy3P (entry 3, Table 1) without energy released or kinetic bottleneck as would be expected for a "loose" transition state. It is noteworthy that for $5 \AA \mathrm{Au}-\mathrm{C}$ bond elongation, the energy of the system is close to the calculated BDE value (difference is lower than $0.01 \mathrm{eV}$ for complex 3-Cy). Similar variations were obtained for the other complexes (Table 1).

Practically, the TS frequency file was built by removing the Au-C stretching frequency at 310 $\mathrm{cm}^{-1}$ and the 5 harmonic frequencies principally impacted by the Au-CO dissociation were modified as follow: $40 \rightarrow 10 \mathrm{~cm}^{-1}, 40 \rightarrow 10 \mathrm{~cm}^{-1}, 340 \rightarrow 68 \mathrm{~cm}^{-1}, 340 \rightarrow 68 \mathrm{~cm}^{-1}, 2305 \rightarrow 2240 \mathrm{~cm}^{-}$ 1. The correction factor of $1 / 4$ for $40 \rightarrow 10 \mathrm{~cm}^{-1}$ and $1 / 5$ for $340 \rightarrow 68 \mathrm{~cm}^{-1}$ is consistent with the $1 / 3$ to $1 / 10$ factors commonly used for loose to very loose TSs [37]. On the other hand, the CO vibrational frequency $2305 \rightarrow 2240 \mathrm{~cm}^{-1}$, was only slightly modified. The resulting Arrhenius pre-exponential factor measured is equal to $10^{15.6} \mathrm{~s}^{-1}$ which is consistent with direct cleavages, usually close to $10^{14} \mathrm{~s}^{-1}$ (and increasing up to $10^{18} \mathrm{~s}^{-1}$ for very loose transition states) [30, 3436].

Uncertainties on critical energies $E_{0}$ were estimated by varying different parameters of the model. BIRD temperatures were changed by $\pm 5{ }^{\circ} \mathrm{C}$ in the simulation. The difference between the lowest and highest experimental temperatures was increased and decreased by $2{ }^{\circ} \mathrm{C}$ in order to reflect an inaccuracy on the slopes of the Arrhenius plot. The four frequencies the most impacted by the Au-CO dissociation were varied as follows: $40 \rightarrow 16 \mathrm{~cm}^{-1}, 40 \rightarrow 16 \mathrm{~cm}^{-1}$, $340 \rightarrow 109 \mathrm{~cm}^{-1}, 340 \rightarrow 109 \mathrm{~cm}^{-1}$ or $40 \rightarrow 6 \mathrm{~cm}^{-1}, 40 \rightarrow 6 \mathrm{~cm}^{-1}, 340 \rightarrow 41 \mathrm{~cm}^{-1}, 340 \rightarrow 41 \mathrm{~cm}^{-1}$ corresponding to an Arrhenius pre-exponential factor change from $10^{14.8}$ to $10^{16.5} \mathrm{~s}^{-1}$, respectively. Again, these values are quite consistent with a direct cleavage [29,34]. The total 
standard deviation of the critical energy determination is the root-sum-squares (RSS) of the critical energy standard deviation obtained by variation of all these parameters.

\section{3. Modification of MassKinetics software for systems outside the REX limit}

For systems outside the REX limit, obtaining $E_{a}$ values requires a complex approach of Master Equation Modeling (MEM) treated excellently by Williams et al [29,30,34,35]. This approach derives from the Lindemann - Hinshelwood model (Eq. (4)) in the case where the only source of activation is the absorption of infrared photons from the surroundings without collisional activation.

$$
A B^{+} \underset{k_{-1, \text { rad }}}{\stackrel{k_{1, \text { rad }}}{\rightleftarrows}}\left[A B^{+}\right]^{*} \stackrel{k_{d}}{\rightarrow} A^{+}+B
$$

In Equation $4, k_{1, \mathrm{rad}}$ and $k_{-1, \mathrm{rad}}$ are rate constants for absorption and emission of infrared photons, respectively, and $k_{d}$ is the unimolecular dissociation rate constant which maybe access by the RRKM-QET theory. Using the steady state approximation, the overall rate constant for the whole process, $k_{u n i}$, is given by Eq. (5).

$$
k_{u n i}=k_{d}\left(\frac{k_{1, \text { rad }}}{k_{-1, \text { rad }}+k_{d}}\right)
$$

For large ions, when the REX limit condition is achieved, the internal energy distribution of the ion population is of a Boltzmann-type and is characterized by a thermodynamic temperature $T$. For intermediate size systems, the internal energy distribution is a temperature truncated in his higher energy part. The amplitude of this truncation depends on the temperature (especially for the highest temperatures), on thermochemical parameters ( $E_{0}$ and $A$ ) related to the reactive ion and on the ion size (number of DoF). In MEM approach, the internal energy distribution of ion population, initially corresponding to a temperature $T$, is divided into thin energy bins. The 
time-evolution of each bin is described considering that the population of precursor ions can either acquire or lose energy by absorption or spontaneous emission of photons. In parallel, those ions may also decompose, whatever the energy bin considered, according to the corresponding microcanonical rate constant $k_{d}$. The time evolution of the entire precursor ions population is described at each moment by the sum of all energy bins populations.

Besides being complicated, Williams model requires a large number of parameters (like transition dipole moments $\mu$ for all optically active modes, and scaling factor [29]) which are often estimated and/or adjusted empirically. In our Equilibrium Thermal Truncated (ETT) model approach proposed herein we use the following concept: in the absence of fragmentation the precursor ion has a thermal energy distribution $P_{t h}(E)$, determined by the temperature $T$ of the environment (ICR cell), which can be calculated by Eq. (6).

$$
P_{t h}(E)=\frac{\rho(E) e^{-\frac{E}{k_{b} T}}}{\int_{0}^{\infty} \rho(E) e^{-\frac{E}{k_{b} T}}}
$$

Where $\rho(E)$ is the density of states, $T$ is the temperature of ICR cell and $k_{b}$ the Boltzmann constant.

When fragmentation occurs, this depletes the high energy fraction of the precursors (depletes the high energy tail of the distribution). At the REX limit energy exchange via photons is very fast, so the energy distribution will remain constant. Outside the REX limit, it will not be possible to restore the thermal energy distribution completely, but it will be a steady state distribution. For the Equilibrium Thermal Truncated model, this truncation is treated as it was done for a characteristic temperature [6-22] with $T_{\text {char }}=T$. We approximate this steady state distribution in the following way: we start from the thermal energy distribution $P_{t h}(E)$ (at the temperature of the environment), and we let fragmentation take place for a certain (arbitrary) time period (called "depletion time", $t$ '). Subsequently, we consider this "depleted thermal" 
energy distribution $P_{\text {ETT }}(E)$ as the steady state distribution characterizing BIRD fragmentation, which can be calculated using the Eq. (7).

$$
P_{E T T}(E)=P_{t h}(E) e^{-k_{d}(E) t^{\prime}}
$$

Where $k_{d}(E)$ is the reaction rate calculated by RRKM method.

At the REX limit the "depletion time" $\left(t^{\prime}\right)$ is zero. The farther away we are from the REX limit, the longer is this "depletion time". Note, we consider "depletion time" as an empirical parameter, which is needed to adjust results of modeling to the experiments.

The advantage of this approach is twofold: first, it is easy to implement and to estimate, how far the system is from the REX limit. Second, it is clear that $t$ ' is the sole empirical parameter related (characteristic) to the studied ion, and treated as such. Note also that the theoretically accurate model proposed by Williams typically also involves empiricism (e.g. scaling of calculated dipole moments by an empirical parameter that we will call $\alpha$ ).

As a summary, $\left[E_{0}, A, \alpha \mu\right]$ and $\left[E_{0}, A, t^{\prime}\right]$ are adjustable parameter sets for MEM and ETT approaches, respectively. For these two approaches, a value for pre-exponential $A$ is no longer experimentally accessible but has to be estimated, usually varying from $10^{14}$ to $10^{16} \mathrm{~s}^{-1}$ for a direct cleavage [28-30]. The critical energy $E_{0}$ and the depletion time $t$ ' were adjusted to fit the experimental Arrhenius plot by the same way than $E_{0}$, and $\alpha \mu$ are adjusted for MEM for a defined pre-exponential factor.

Note that the MEM approach is more accurate than the ETT approach thanks to the calculation of transition dipole moments $\mu$ of the ion for all optically active modes (nevertheless empirically adjusted by an $\alpha$ coefficient) whereas $t^{\prime}$ is a purely empirical parameter. However, for the ETT model, $t^{\prime}$ parameter remains constant whatever the temperature (an experimental 
variation of about $40^{\circ} \mathrm{C}$ is used for our BIRD measurements) considering that $\left(k_{1, \mathrm{rad}}+k_{-1, \mathrm{rad}}\right)$ does not vary with temperature whereas a slight variation is taken into account in the MEM approach [30].

\section{4. Validation of the modeling procedure using data from the literature}

Before carrying out the modeling of the experimental lines obtained for the $[\mathrm{LAu}-\mathrm{CO}]^{+}$ complexes, the ETT approach developed under MassKinetics was first tested on the basis of literature data processed by MEM approach. Previously published thermochemical data obtained by MEM for proton-bound homodimers of N,N-dimethylacetamide $(\mathrm{N}, \mathrm{N}-\mathrm{DMA} \cdot \mathrm{N}, \mathrm{N}-$ DMA), alanine (ALA•ALA) and lysine (LYS $\bullet$ LYS ) were used as reference to validate our approach [29]. The transition state for proton bound dimer was described in order to reach a pre-exponential factor $\mathrm{A}=10^{15.5 \pm 1} \mathrm{~s}^{-1}$ that characterized a "loose" transition state as proposed by Williams and coworkers [29]. To this end, the reaction coordinate was fixed at $2200 \mathrm{~cm}^{-1}$ and five frequencies were modified as follows: $400 \rightarrow 70 \mathrm{~cm}^{-1}, 400 \rightarrow 70 \mathrm{~cm}^{-1}, 800 \rightarrow 600 \mathrm{~cm}^{-1}$, $800 \rightarrow 600 \mathrm{~cm}^{-1}, 2200 \rightarrow 2000 \mathrm{~cm}^{-1}$.

In the case of proton-bound homodimers of $N, N$-dimethylacetamide ( $N, N$-DMA), straight line fitting lead to measured thermochemical data $E_{a}$ measd $=0.99 \mathrm{eV}$ and $A_{\text {measd }}=10^{10.1} \mathrm{~s}^{-1}$, similar to those experimentally obtained by Williams and coworkers [29], was constructed and treated using MassKinetics software. Note that these "measured Arrhenius parameters" are also called “apparent Arrhenius parameters" [28]. By using our ETT model, the obtained $E_{0}$ is equal to $1.24 \pm 0.06 \mathrm{eV}$ and is close to the value obtained by MEM $(1.25 \pm 0.05 \mathrm{eV})$ considering a preexponential factor $A=10^{15.5 \pm 1} \mathrm{~s}^{-1}$ (see SI). Similar results are obtained for alanine (ALA•ALA) and lysine $(\mathrm{LYS} \cdot \mathrm{LYS})$ dimers, leading to a difference with the MEM approach lower than 0.05 eV (Table 1). Times of depletion $t^{\prime}$ of $5.5 \cdot 10^{-3}, 4.0 \cdot 10^{-3}, 5.0 \cdot 10^{-3} \mathrm{~s}$ were obtained to fit Arrhenius 
lines for proton-bound homodimers of $N, N$-dimethylacetamide ( $N, N$-DMA), alanine $(\mathrm{ALA} \bullet A L A)$ and lysine $(\mathrm{LYS} \bullet \mathrm{LYS})$, respectively.

\section{Table 1}

Thermochemical parameters of proton-bound dimers

\begin{tabular}{|c|c|c|c|c|}
\hline \multirow{2}{*}{ Compounds } & \multirow{2}{*}{$\begin{array}{l}E_{a \text { measd }}{ }^{a} \\
(\mathrm{eV})\end{array}$} & \multirow{2}{*}{$\begin{array}{l}A_{\text {measd }} b \\
\left(\mathrm{~s}^{-1}\right)\end{array}$} & \multicolumn{2}{|l|}{$E_{0}(\mathrm{eV})$} \\
\hline & & & $\mathrm{MEM}^{c}$ & $\mathrm{ETT}^{d}$ \\
\hline$N, N$-DMA & 0.99 & $10^{10.1}$ & $1.25 \pm 0.05$ & $1.24 \pm 0.06$ \\
\hline $\mathbf{A L A} \cdot \mathbf{A L A}$ & 0.92 & $10^{10.1}$ & $1.12 \pm 0.03$ & $1.13 \pm 0.05$ \\
\hline LYS•LYS & 0.93 & $10^{11.0}$ & $1.15 \pm 0.05$ & $1.11 \pm 0.05$ \\
\hline
\end{tabular}

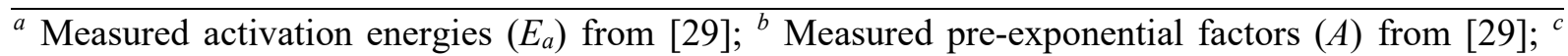
Corrected critical energies ( $\left.E_{0}\right)$ obtained by Master Equation Modeling from [29] modeling using $A=$ $10^{15.5 \pm 1} \mathrm{~s}^{-1} ;{ }^{d}$ Corrected $E_{0}$ values obtained with an Equilibrium Thermal Truncated (ETT) internal energy distribution and RRKM modeling by using $A=10^{15.5 \pm 1} \mathrm{~s}^{-1}$.

Small differences are observed between the $E_{0}$ values obtained with by MEM and ETT models for the 3 proton-bound dimers. It confirmed to us the suitability of the ETT internal energy distribution model for the determination of binding energies. In the following, we have accordingly applied this model to the case of our gold carbonyl complexes.

\section{Results and discussion}

As outlined in the introduction, the BIRD is one of the few mass spectrometry techniques that can measure the dissociation energies of rather weak interactions. This technique is more adequate and easier to use for large molecular systems maintained under thermal equilibrium during their fragmentation, hence approaching the REX limit [28]. Thus, [LAu-CO] ${ }^{+}$complexes with $\mathrm{L}=\mathrm{Me}_{3} \mathrm{P}, \mathrm{Et}_{3} \mathrm{P}$ and $i \mathrm{Pr}_{3} \mathrm{P}$ as well as complexes with $\mathrm{L}=\mathrm{Ph}_{2} \mathrm{MeP}$ and $\mathrm{L}=\mathrm{PhMe}_{2} \mathrm{P}$, studied in a previous paper [5], were not considered here because of their small size and their low 
number of oscillators $(\mathrm{DoF}<100)$. Indeed, the maximum temperature achievable with our BIRD heating system is $140{ }^{\circ} \mathrm{C}$ and, in such conditions, the IPr and MIC carbene complexes previously studied (see SI for structures) did only very slightly decompose because of their high $E_{0}$ values (their calculated BDEs are $1.82 \mathrm{eV}$ and $1.76 \mathrm{eV}$, respectively) and were therefore ineligible to our study. As a consequence, only 8 [LAu-CO $]^{+}$complexes from the 16 previously studied by CID [5], were found suitable to achieve this study. These selected $\mathbf{8}$ complexes that were finally selected are reported in Table 2. They are unstable at ambient temperature and are not commercial. Thus, they were synthesized in-situ by ion-molecule reactions (IMR) in the hexapolar collision cell of the mass spectrometer [32,38,39]. Note that minor amounts $(<5 \%)$ of highly fragile and readily dissociating $\left[\mathrm{LAu}-\mathrm{N}_{2}\right]^{+}$or $[\mathrm{LAu}-\mathrm{OC}]^{+}$complexes that were observed in the triple quadrupole mass spectrometer (same $\mathrm{m} / \mathrm{z}$ as [LAu-CO] ${ }^{+}$species) [5], are decomposed before being isolated inside the ICR cell thanks to $1 \mathrm{~s}$ reaction time inside the collision cell.

\section{Table 2}

Structures, numbers of Degrees of Freedom (DoF) and masses for the gold(I) carbonyl complexes studied in this work.

\begin{tabular}{|c|c|c|c|c|}
\hline Entry & Complex & Structure & DoF & mass $(\mathrm{Da})$ \\
\hline 1 & 1-pOMe & & 141 & 577 \\
\hline 2 & 2-biPh & $\begin{array}{c}t-\mathrm{Bu}-\mathrm{P}-\mathrm{Au}-\mathrm{CO} O \\
t-\mathrm{Bu}{ }^{\oplus}\end{array}$ & 147 & 523 \\
\hline 3 & 3-Сy & $\begin{array}{c}\mathrm{Cy} \\
\mathrm{Cy}-\mathrm{P}-\mathrm{Au}-\mathrm{CO} \\
\mathrm{Cy}\end{array}$ & 159 & 505 \\
\hline 4 & 4- $t \mathrm{Bu}$ & $\underset{t-\mathrm{Bu}-\mathrm{Bu}-\mathrm{P}-\mathrm{Au}-\mathrm{CO}}{t-\mathrm{Bu}}$ & 123 & 427 \\
\hline 5 & 5-Ph & 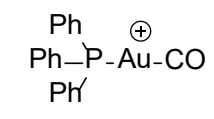 & 105 & 487 \\
\hline 6 & 6- $p \mathrm{CF}_{3}$ & (I)P & 132 & 691 \\
\hline
\end{tabular}


After BIRD activation at various temperatures of the complexes, kinetic plots such as those presented in Figure 1 for complex 7-OtBuPh were obtained. Results for complexes 1-8 are given in SI. The resulting Arrhenius plots obtained for complexes 1-8 are shown in Figure 2 and, the corresponding activation energies and the measured Arrhenius pre-exponential factors are reported in Table 3. Due to an $\mathrm{R}^{2}=0.94$ for the Arrhenius line of the 8-OPh complex (see SI) much lower than that of other complexes with $\mathrm{R}^{2}$ greater than 0.995 , the 8 -OPh complex was no longer studied. This complex decomposes very slightly and is therefore accessible for our BIRD apparatus.

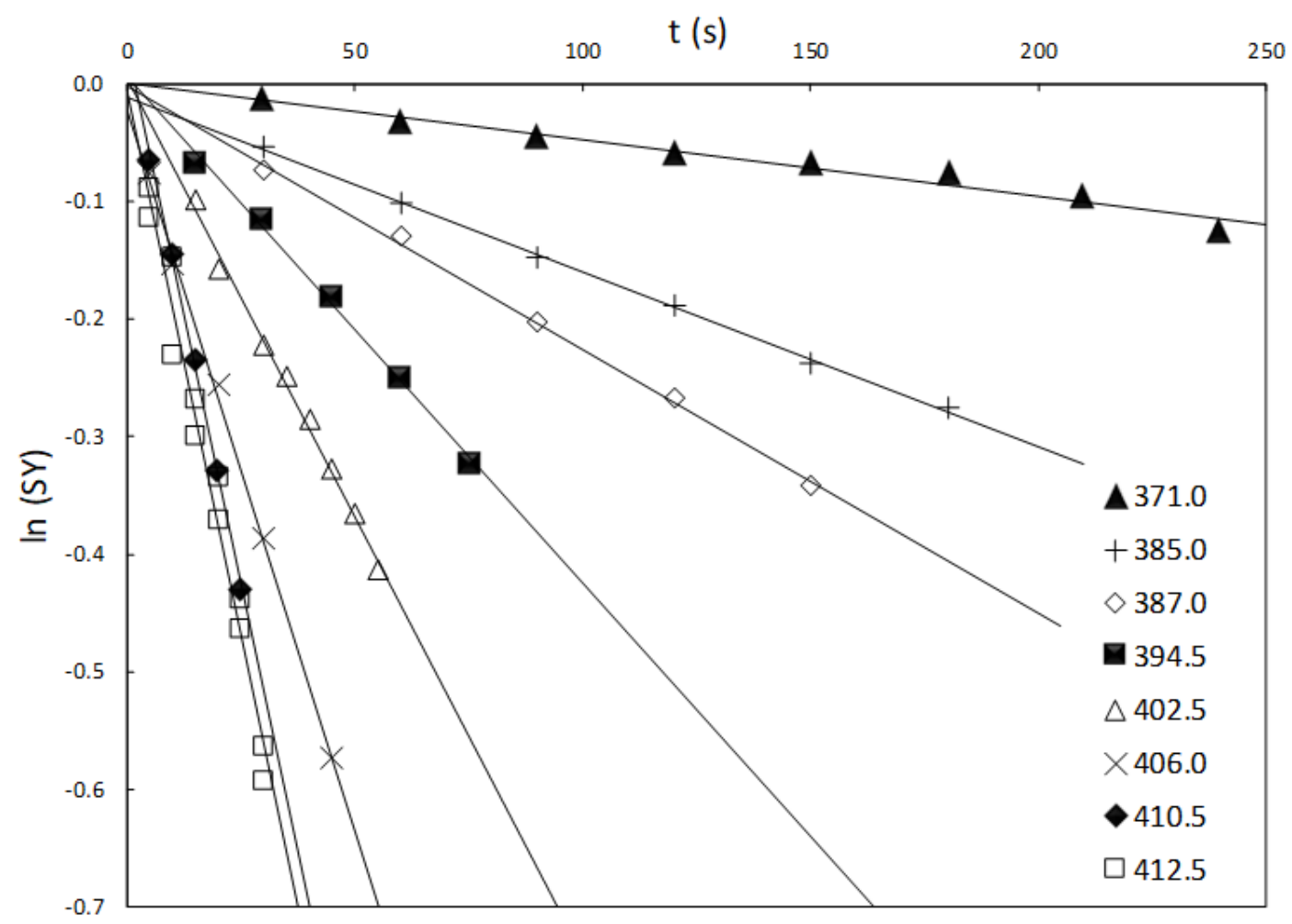

Fig. 1. Plots of the natural logarithms of the survival yield for 7-OtBuPh complex as a function of reaction time at temperatures ranging from 371.0 to $412.5 \mathrm{~K}$. 


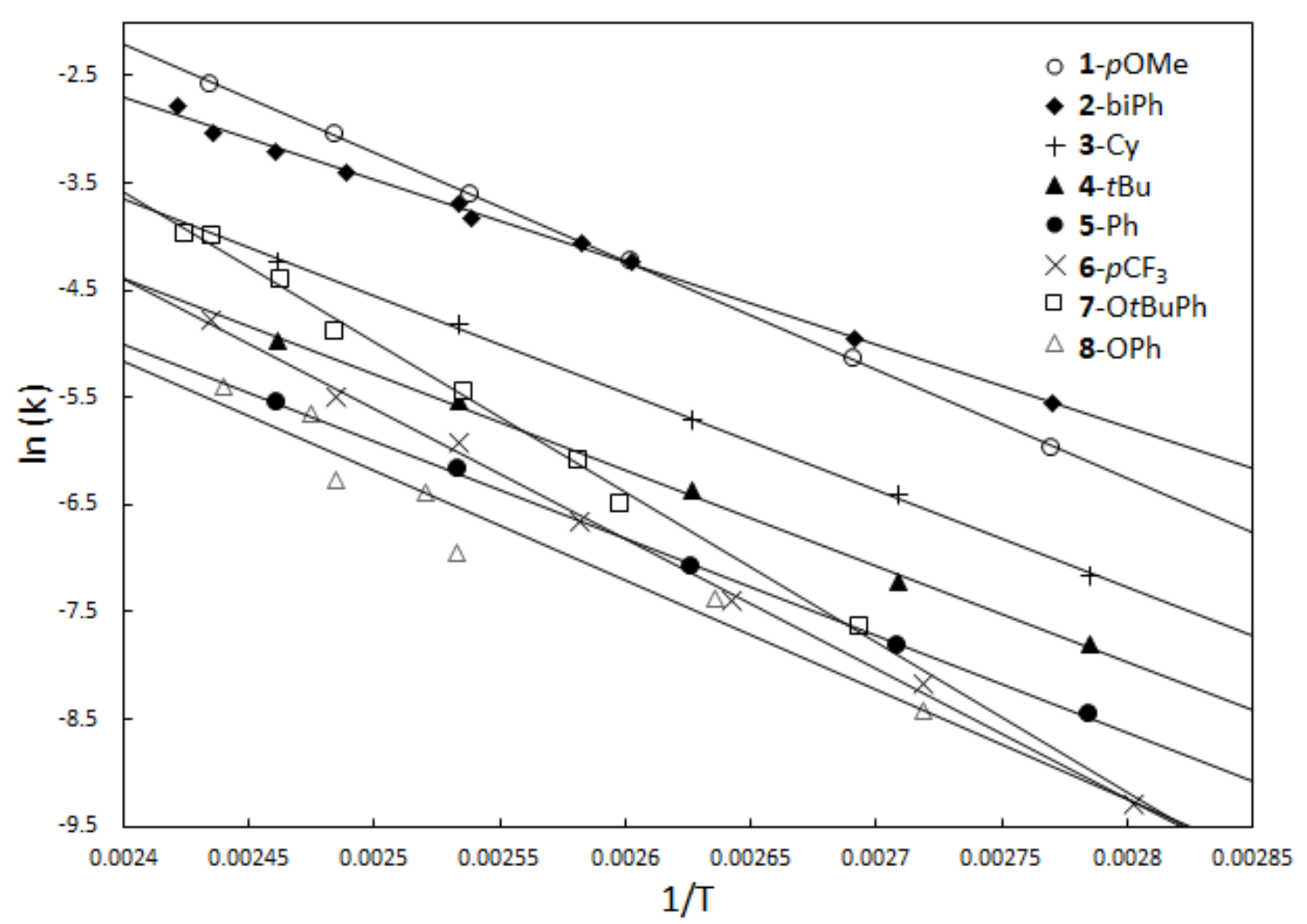

Fig. 2. Arrhenius plots for the dissociation of the eight $[\mathrm{LAu}-\mathrm{CO}]^{+}$complexes studied.

\section{Table 3}

Theoretical and experimental thermochemical data obtained for complexes 1-8

\begin{tabular}{|c|c|c|c|c|c|c|c|}
\hline Entry & Complex & $\begin{array}{c}\mathrm{BDE}^{a} \\
(\mathrm{eV})\end{array}$ & $\begin{array}{c}E_{a \text { measd }}{ }^{b} \\
(\mathrm{eV})\end{array}$ & $\begin{array}{c}A \text { measd }^{c} \\
\left(\mathrm{~s}^{-1}\right)\end{array}$ & $\begin{array}{l}E_{0}{ }^{d} \\
(\mathrm{eV})\end{array}$ & $\begin{array}{c}\Delta_{\mathrm{BDE}-\mathrm{E} 0}{ }^{e} \\
(\mathrm{eV})\end{array}$ & $\begin{array}{l}t^{\prime} f \\
(\mathrm{~s})\end{array}$ \\
\hline 1 & 1-pOMe & $1.38_{0}$ & 0.87 & $10^{9.6}$ & $1.20_{5}( \pm 0.04)$ & $0.17_{5}$ & 0.05 \\
\hline 2 & 2-biPh & $1.38_{5}$ & 0.66 & $10^{6.8}$ & $1.14_{5}( \pm 0.04)$ & 0.24 & 0.25 \\
\hline 3 & 3-Cy & $1.44_{5}$ & 0.78 & $10^{7.8}$ & $1.20_{0}( \pm 0.04)$ & $0.24_{5}$ & 0.35 \\
\hline 4 & 4- $t \mathrm{Bu}$ & $1.45_{5}$ & 0.77 & $10^{7.4}$ & $1.205( \pm 0.04)$ & 0.25 & 0.4 \\
\hline 5 & 5-Ph & 1.465 & 0.78 & $10^{7.3}$ & $1.205( \pm 0.04)$ & 0.26 & 0.5 \\
\hline 6 & 6- $p \mathrm{CF}_{3}$ & $1.52_{0}$ & 1.05 & $10^{10.7}$ & $1.30( \pm 0.05)$ & 0.22 & 0.15 \\
\hline 7 & 7-OtBuPh & 1.535 & 1.21 & $10^{13.0}$ & $1.34( \pm 0.03)$ & $0.19_{5}$ & 0.15 \\
\hline 8 & 8-OPh & $1,55_{0}$ & 0,88 & $10^{8.4}$ & $1.27( \pm 0.06)$ & 0.28 & 0.4 \\
\hline
\end{tabular}

${ }^{a}$ Computed BDEs using the PBE0-D3BJ/def2-TZVP level of theory [5]; ${ }^{b}$ Measured activation energies $\left(E_{a}\right) ;{ }^{c}$ Measured pre-exponential factors $(A) ;{ }^{d}$ Corrected critical energy values $\left(E_{0}\right)$ obtained by ETT modeling using $A=10^{15.6} \mathrm{~s}^{-1}$ and their uncertainties in brackets; ${ }^{e}$ Differences between BDE and $E_{0}$ values for the eight $[\mathrm{LAu}-\mathrm{CO}]^{+}$complexes studied. ${ }^{f}$ Time of depletion obtained by ETT modeling to fit the Arrhenius plots, see more details in the text. 
The numbers of DoFs of the 7 remaining studied complexes are relatively low and between 105 to 330 . The measured activation energies $\left(E_{a}\right.$ measd $)$ obtained by BIRD vary from $0.66 \mathrm{eV}$ (2biPh) to $1.21 \mathrm{eV}(7-\mathrm{O} t \mathrm{BuPh})($ Table 3) and are therefore much lower than the calculated BDEs which range between $1.38 \mathrm{eV}(\mathbf{1}-p \mathrm{OMe})$ and $1.53_{5} \mathrm{eV}(\mathbf{7}-\mathrm{O} t \mathrm{BuPh})$ (Table 2). The measured Arrhenius pre-exponential factors $(A$ measd $)$ range from $10^{6.8}$ up to $10^{13.0} \mathrm{~s}^{-1}$ and are also far from the estimated $A=10^{15.6} \mathrm{~s}^{-1}$. These low values for pre-exponential factors measured by BIRD experiments confirm that the complexes are not in REX limit, even though the largest system (7-O $t \mathrm{BuPh}, \mathrm{DoF}=330)$ approaches these conditions with a measured $A=10^{13.0} \mathrm{~s}^{-1}$. It follows that all measured pre-exponential factors and activation energies are lowered, especially for the smallest complexes $[29,30]$.

For the ETT model, the overall rate constants (Eq. (5)), are determined for the different cell temperatures by the fitting of Arrhenius experimental lines $\ln k=f(1 / T)$. As previously mentioned, these overall rate constants are obtained by truncation of the thermal distribution $T$ after determining a time lapse $t^{\prime}$ of depletion. In the case of 7-O $t \mathrm{BuPh}$ and $\mathbf{5}-\mathrm{Ph}$ it is clear that internal energy distributions and observed truncations depend on the size of the system (Figure 3) and also on the temperature (see SI). For the 7-OtBuPh, the inaccuracy of the resulting time lapse $t^{\prime}$ of $0.15 \mathrm{~s}$ is estimated to be a factor 3 (see SI). A variation by a factor of ten from 0.015 $\mathrm{s}$ up to $1.5 \mathrm{~s}$ results in a small change of $E_{0}$ values $(1.35 \mathrm{eV}$ down to $1.31 \mathrm{eV}$, respectively) and to the inability to fit the experimental data (see SI). 

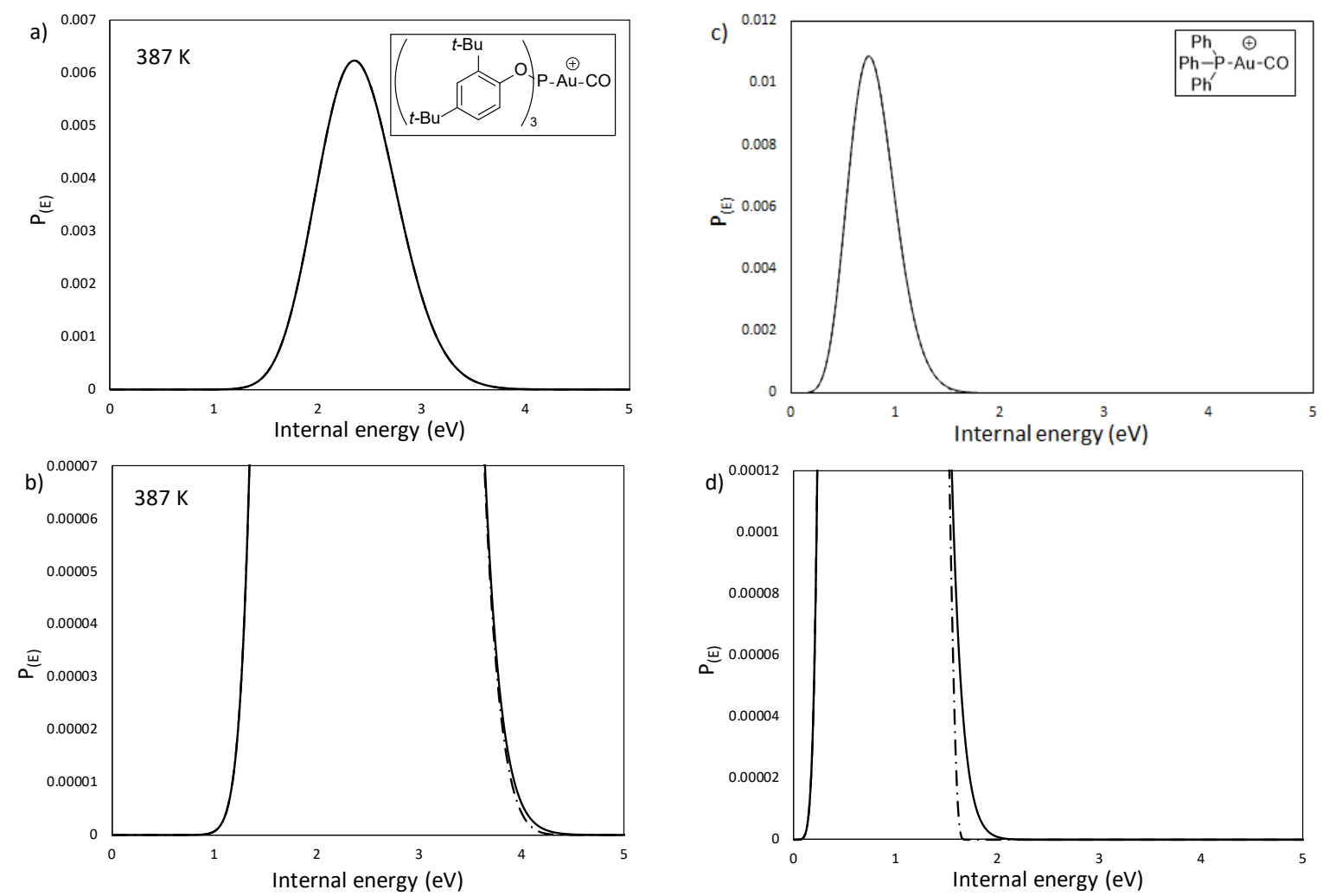

Fig. 3. a) Thermal internal energy distribution for complex 7-O $t \mathrm{BuPh}$ calculated at $T=387 \mathrm{~K}$ before depletion (line) and after depletion of $t^{\prime}=0.15 \mathrm{~s}$ (dash-dot line), this truncation corresponds to $0,0004 \%$ of the initial population b) magnification x100 c) Thermal internal energy distribution for complex 5-Ph calculated at $T=387 \mathrm{~K}$ before depletion (line) and after depletion of $t^{\prime}=0.5 \mathrm{~s}$ (dash-dot line), this truncation corresponds to $0.0019 \%$ of the initial population d) magnification $\mathrm{x} 100$.

Critical energies values are thus determined for the 7 complexes from the experimental Arrhenius plots using MassKinetics and ETT approach. These results are compared with the measured $E_{a}$ value (Table 3). The largest difference between $E_{0}$ and $E_{a}$ is observed for 2-biPh ( $1.14 \mathrm{eV} v s .0 .66 \mathrm{eV}$, respectively) whereas for the large 7-O $t \mathrm{BuPh}$ system, the calculated $E_{0}$ value $(1.34 \mathrm{eV})$ only slightly differs from the experimentally obtained $E_{a}(1.21 \mathrm{eV})$. In Figure 4, a comparison between measured $E_{a}$, calculated BDEs and $E_{0}$ resulting from MassKinetics simulations is also presented. 


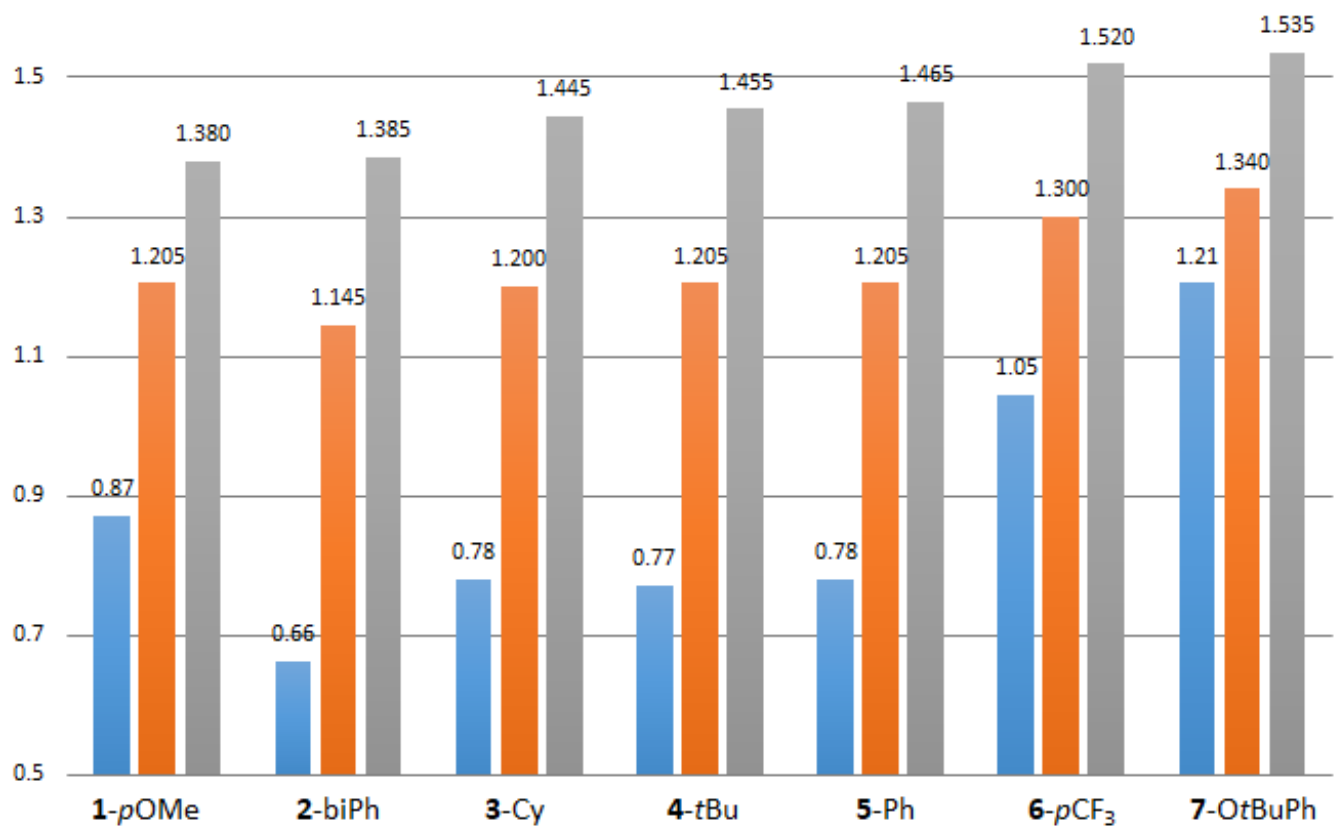

Fig. 4. Comparison of measured $E_{a}$ (blue), $E_{0}$ obtained by modeling using MassKinetics software and ETT approach considering $A=10^{15.6} \mathrm{~s}^{-1}$ (orange) and calculated BDE (ref. [5]) (grey). Data are reported in $\mathrm{eV}$.

The differences between the calculated BDEs and the $E_{0 s}$ obtained by RRKM modeling using MassKinetics vary from $0.17_{5} \mathrm{eV}(\mathbf{1}-p \mathrm{OMe})$ up to $0.26 \mathrm{eV}($ 5-Ph) (Table 3). This large gap may be attributed to the level of calculations used, which eventually overestimates the bond dissociation energy even though single point energy calculation of the dissociation of CO were performed at a high level of theory (DLPNO-CCSD(T)/CC-PVTZ-PP). On the contrary, critical energies may be underestimated due to the fixed value used for the pre-exponential factor $(A=$ $\left.10^{15.6} \mathrm{~s}^{-1}\right)$. The correlation plot obtained between BDEs and $E_{0 S}$ shown in Figure 5 is nevertheless exhibiting a reasonably linear tendency. 


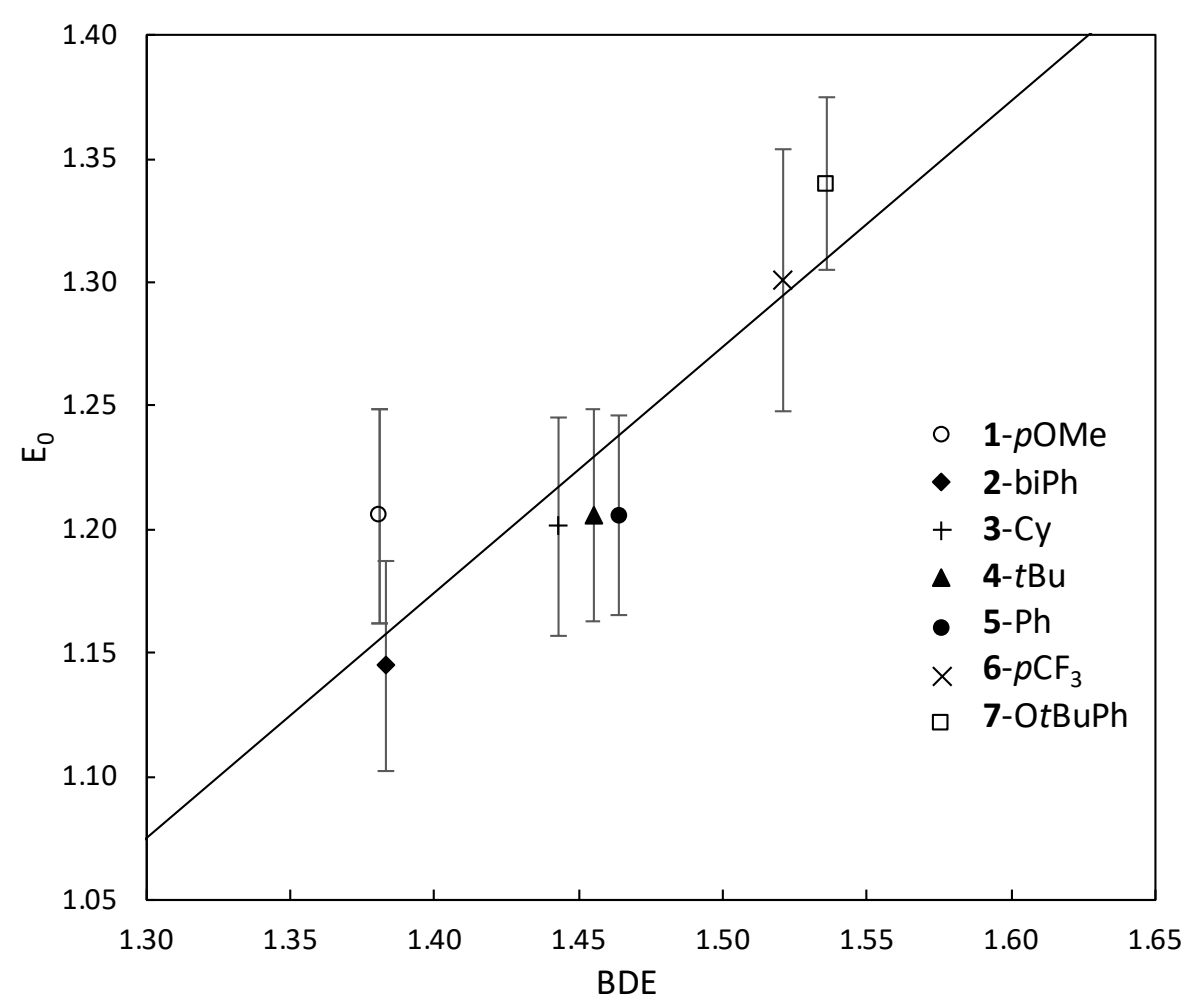

Fig. 5. Comparison of calculated BDEs (eV) (ref. [5]) and $E_{0}$ obtained with BIRD measurements and ETT modeling using MassKinetics software and considering $A=10^{15.6 \pm 0.9} \mathrm{~s}^{-}$ 1 .

The difference of calculated BDE between the two complexes 3-Cy and 4- $t \mathrm{Bu}(0.01 \mathrm{eV})$ is close to the difference of $E_{0}$ values $\left(0.00_{5} \mathrm{eV}\right)$. A much larger difference $(0.07 \mathrm{eV})$ was obtained from our previous CID measurements (see SI) [5]. This feature could be explained by the fact that in our previous study only the number of oscillators was taken into account during the energy calibration for CID without considering the nature of these oscillators. A very compact $t \mathrm{Bu}$ group is storing however less energy per collision than the average value of the other complexes and thus its $E_{0}$ value may have been overestimated using CID. On the contrary, the 1-pOMe complex slightly deviates from this trend and shows the lowest delta of $0.17_{5} \mathrm{eV}$ between BDE and $E_{0}$ (Table 3, entry 1). In this case, the time lapse $t$ ' of depletion, leading to an ETT internal energy distribution, is relatively short, i.e. $0.05 \mathrm{~s}$ (Table 3, entry 1) when compared with values used for other complexes (from $0.15 \mathrm{~s}$ for $7-\mathrm{O} t \mathrm{BuPh}$ to $0.5 \mathrm{~s}$ for 5-Ph, Table 3, entry 7 and 5 respectively). The relevance of the modeled Arrhenius plot (Figure 2) depends on this lapse 
time $t$ ' of depletion that correlates with the critical energy and the pre-exponential factor used. The calculated BDEs for 1- $p \mathrm{OMe}$ and 2-biPh complexes are almost identical (1.38 eV and 1.385 eV respectively) whereas the experimental Arrhenius lines show different slopes despite a close number of DoFs $\left(E_{a \text { measd }}=0.87 \mathrm{eV}\right.$ and $0.66 \mathrm{eV}$ for number of DoFs 141 and 148, respectively). This result suggests either that one of the calculated BDEs is not correct or that the preexponential factor of 2-biPh complex is lower than for the other complexes due to possible internal rearrangements, as the ligand interact when $\mathrm{CO}$ is lost [5]. This lower pre-exponential factor would bring 2-biPh complex closer to the REX limit than the 1-pOMe complex. Nevertheless, this source of error is taken into account in the calculation of uncertainties of the TS. For the 2-biPh, the variation of the 5 frequencies involved during the fragmentation is similar to those of the other complexes even if it is observed for a higher elongation of $5.4 \AA$. Perhaps differences in transition states could have been obtained by using the PLS transition state and hindered rotors approach instead of modeling a loose transition state as proposed herein $[37,40]$.

\section{Conclusion}

The decomposition of 8 [LAu-CO $]^{+}$complexes formed inside a modified FT-ICR mass spectrometer was investigated using BIRD experiments. Arrhenius activation energies for the gold-carbon bond dissociation were measured. The measured pre-exponential factors obtained from Arrhenius plots are significantly lower than the calculated value of $10^{15.6} \mathrm{~s}^{-1}$ obtained by elongation of the Au-CO bond (from the DFT calculations), characteristic of a "loose" transition state. This indicates that the complexes did not reach the REX limit in our experimental conditions and that the measured critical energies were consequently underestimated compared to the expected values. An accurate fit of the measured dissociation rate constant was obtained 
for the 8 complexes using an equilibrium thermal truncated internal energy (ETT) distributions model recently implemented in the MassKinetics software. This model implies to define the transition states and to calculate overall rate constants achieved after the truncation of the initial thermal internal energy distributions at temperature $T$ for the BIRD experiments. Critical energies obtained using this model are around $0.22 \mathrm{eV}$ lower than previously calculated BDEs at the PBE0-D3BJ/def2-TZVP level of theory for the complexes. Nevertheless, the $E_{0}$ value for the large complex (7-Ot $\mathrm{BuPh})$, close to the REX limit and therefore poorly corrected by ETT modeling, suggests that the BDE calculated values are certainly overestimated by about $0.2 \mathrm{eV}$ or pre-exponential factor used is underestimated.

From this work, several conclusions can be drawn. From a chemical point of view, a relation between ligand electronic effects in $[\mathrm{LAu}-\mathrm{CO}]^{+}$complexes and dissociation energy of the AuCO bond exists and can be used as a descriptor to classify the ligands according to their global electronic properties and subtle effects can be accurately observed. In contrast to our previous CID study, a more restricted range of complexes can be dissociated by BIRD experiments. However, thanks to the use of ETT modeling that takes into account thermochemical parameters related to the decomposing ion and its size, absolute and more precise values are obtained.

\section{Acknowledgments}

This work was funded by the ANR ELEEM2 project, grant ANR-13-BS07-0001 of the French Agence Nationale de la Recherche. This work has been supported by Labex ARCANE, by CBH-EUR-GS (ANR-17-EURE-0003) and by the National Research, Development and Innovation Office (K 131762). Financial support from the National FT-ICR network (FR 3624 CNRS) for conducting the research is gratefully acknowledged.

\section{Supporting information}

Supplementary data to this article can be found online at https://

\section{Note}


The authors declare no competing financial interests or personal relationships that could have appeared to influence the work reported in this paper. 


\section{References}

1) a) Gold Catalysis: An Homogenous Approach, ed. F. D. Toste and V. Michelet, Imperial College Press, London, 2014; b) A. Nijamudheen and Ayan Datta, Gold-Catalyzed CrossCoupling Reactions: An Overview of Design. Strategies, Mechanistic Studies, and Applications. Chem. Eur. J. 2020, 26, 1442-1487.

2) For recent reviews, see: a) Y.Wei, M. Shi, ACS Catal. 6 (2016) 2515-2524; b) R. J. Harris, R. A. Widenhoefer, Chem. Soc. Rev. 45 (2016) 4533-4551; c) D. Pflästerer, A.S.K. Hashmi, Chem. Soc. Rev. 45 (2016) 1331-1367.

3) R. Dorel, A. M. Echavarren, Chem. Rev. 115 (2015) 9028-9072.

4) a) D. Malhotra, G. B. Hammond, B. Xu, (2014) Ligand Design in Gold Catalysis and Chemistry of Gold-Oxonium Intermediates. In: Slaughter L. (eds) Homogeneous Gold Catalysis. Topics in Current Chemistry, vol 357. Springer, Cham; b) J. Schieß1, J. Schulmeister, A. Doppiu, E. Wörner, M. Rudolph, R. Karch, A. S. K. Hashmi, Adv. Synth. Catal. 360 (2018) 3949-3959; c) F. Jaroschik, A. Simonneau, G. Lemière, K. Cariou, N. Agenet, H. Amouri, C. Aubert, J.-P. Goddard, D. Lesage, M. Malacria, Y. Gimbert, V. Gandon, L. Fensterbank, ACS Catal. 6 (2016) 5146-5160; d) L. D’Amore, G. Ciancaleoni, L. Belpassi, F. Tarantelli, D. Zuccaccia, P. Belanzoni, Organometallics 36 (2017) 2364-2376.

5) D. Gatineau, D. Lesage, H. Clavier, H. Dossmann, C. Chan, A. Milet, A. Memboeuf, R. B. Cole, Y. Gimbert, Bond dissociation energies of carbonyl gold complexes: a new descriptor of ligand effects in gold(I) complexes? Dalton Trans. 47 (2018) 15497-15505.

6) D. Lesage, S. Mezzache, Y. Gimbert, H. Dossmann, J.-C. Tabet. Extended kinetic method and RRKM modeling to reinvestigate proline's proton affinity and approach the meaning of effective temperature. European Journal of Mass Spectrometry 25 (2019) 219-228.

7) P. Bayat, D. Lesage, R. B. Cole, Low energy collision induced dissociation (low energy CID), collision induced dissociation (CID), and higher energy collision dissociation (HCD) mass spectrometry for structural elucidation of saccharides and clarification of their dissolution mechanism in DMAc/LiCl. J. Mass Spectrom. 53 (2018) 705-716.

8) C. Collette, E. De Pauw, Calibration of the internal energy distribution of ions produced by electrospray, Rapid Commun. Mass Spectrom. 12 (1998) 165-170.

9) L. Drahos, M. A. Heeren Ron, C. Collette, E. De Pauw, K. Vekey Thermal energy distribution observed in electrospray ionization. J. Mass Spectrom. 34 (1999) 1373-1379.

10) A. Pak, D. Lesage, Y. Gimbert, K. Vekey, J.-C. Tabet, Internal energy distribution of peptides in electrospray ionization : ESI and collision-induced dissociation spectra calculation. J. Mass Spectrom. 43 (2008) 447-455.

11) V. Gabelica, E. De Pauw, Internal energy and fragmentation of ions produced in electrospray sources. Mass Spectrom. Rev. 24 (2004) 566-587.

12) J. Naban-Maillet, D. Lesage, A. Bossée, Y. Gimbert, J. Sztaray, K. Vekey, J.-C. Tabet, Internal energy distribution in electrospray ionization. J. Mass Spectrom. 40 (2005) 1-8.

13) J. E. Carpenter, C. P. McNary, A. Furin, A. F. Sweeney, P. B. Armentrout, How Hot are Your Ions Really? A Threshold Collision-Induced Dissociation Study of Substituted Benzylpyridinium "Thermometer" Ions. J. Am. Soc. Mass Spectrom. 28 (2017) 1876-1888. 
14) D. Touboul, M. C. Jecklin, R. Zenobi, Ion internal energy distributions validate the charge residue model for small molecule ion formation by spray methods. Rapid Commun. Mass Spectrom. 22 (2008) 1062-1068.

15) E. A. Solano, S. Mohamed, P. M. Mayer. Modeling collision energy transfer in APCI/CID mass spectra of PAHs using thermal-like post-collision internal energy distributions. J. Chem. Phys. 145 (2016) 164311/1-164311/11.

16) M. Dumlao, G. N. Khairallah, W. A. Donald, Internal Energy Deposition in Dielectric Barrier Discharge Ionization is Significantly Lower than in Direct Analysis in Real-Time Mass Spectrometry. Aust. J. Chem. 70 (2017) 71219-71226.

17) C. Y. Hampton, C. J. Silvestri, T. P. Forbes, M. J. Meacham, A. G. Fedorov, F. L. Gegertekin, F. M. Ferandez, Comparison of the internal energy deposition of venturi-assisted electrospray ionization and a venturi-assisted array of micromachined ultrasonic electrosprays (AMUSE). J. Am. Soc. Mass. Spectrom. 19 (2008) 1320-1329.

18) J. F. Greisch, V. Gabelica, F. Remacle, E. De Pauw, Thermometer ions for matrixenhanced laser desorption/ionization internal energy calibration. Rapid Commun. Mass Spectrom. 17 (2003)1847-1854.

19) R. A. Picca, C. D. Calvano, N. Cioffi, F. Plamisano, Mechanisms of Nanophase-Induced Desorption in LDI-MS. A Short Review. Nanomaterials 7 (2017) 75/1-20.

20) G. Luo, Y. Chen, G. Siuzdak, A. Vertes, Surface Modification and Laser Pulse Length Effects on Internal Energy Transfer in DIOS. J Phys Chem B 109 (2005) 24450-24456.

21) F. Ichou, D. Lesage, X. Machuron-Mandard, C. Junot, R. B. Cole, J.-C. Tabet, Collision cell pressure effect on CID spectra pattern using triple quadrupole instruments: a RRKM modeling. J. Mass Spectrom. 48 (2013) 179-186.

22) F. Ichou, A. Schwarzenberg, D. Lesage, S. Alves, C. Junot, X. Marchuron-Mandard, J.C. Tabet, Comparison of the activation time effects and the internal energy distributions for the CID, PQD and HCD excitation modes. J. Mass Spectrom. 49 (2014) 498-508.

23) R. A. Marcus, O. K. Rice, The Kinetics of the Recombination of Methyl Radicals and Iodine Atoms. J. Phys. Chem. 55 (1951) 894-908.

24) H. M. Rosenstock, M. B. Wallenstein, A. L. Wahrhaftig, H. Eyring, Absolute Rate Theory for Isolated Systems and the Mass Spectra of Polyatomic Molecules. Proceedings of the National Academy of Sciences of the United States of America 38 (1952) 667-678.

25) C. Lifshitz, Kinetic Shifts, Eur. J. Mass Spectrom. 8 (2002) 85-98.

26) R. C. Dunbar, Kinetics of Thermal Unimolecular Dissociation by Ambient Infrared Radiation. The Journal of Physical Chemistry 98 (1994) 8705-8712.

27) D. Thoelmann, D. S. Tonner, T. B. McMahon, Spontaneous Unimolecular Dissociation of Small Cluster Ions, $\left(\mathrm{H}_{3} \mathrm{O}^{+}\right) \mathrm{Ln}$ and $\mathrm{Cl}-\left(\mathrm{H}_{2} \mathrm{O}\right) n(\mathrm{n}=2-4)$, under Fourier Transform Ion Cyclotron Resonance Conditions. J. Phys. Chem. 98 (1994) 2002-2004.

28) R. C. Dunbar, BIRD (blackbody infrared radiative dissociation): Evolution, principles, and applications. Mass Spectrom. Rev. 23 (2004) 127-158.

29) W. D. Price, P. D. Schnier, E. R. Williams, Binding energies of the proton-bound amino acid dimers Gly·Gly, Ala·Ala, Gly·Ala, and Lys $\cdot$ Lys measured by blackbody infrared radiative dissociation. The Journal of Physical Chemistry B 101 (1997) 10664-10673. 
30) W. D. Price, E. R. Williams, Activation of Peptide Ions by Blackbody Radiation: Factors That Lead to Dissociation Kinetics in the Rapid Energy Exchange Limit. J. Phys. Chem. A 101 (1997) 8844-8852.

31) L. Drahos, K. Vékey MassKinetics: a theoretical model of mass spectra incorporating physical processes, reaction kinetics and mathematical descriptions. J. Mass Spectrom. 36 (2001) 237-263.

32) P. Bayat, D. Gatineau, D. Lesage, S. Marhabaie, A. Martinez, R. B. Cole, Investigation of activation energies for dissociation of host-guest complexes in the gas phase using lowenergy collision induced dissociation. J. Mass Spectrom. 54 (2019) 437-448.

33) M. J. Frisch, G. W. Trucks, H. B. Schlegel, G. E. Scuseria, M. A. Robb, J. R. Cheeseman, G. Scalmani, V. Barone, B. Mennucci, G. A. Petersson, H. Nakatsuji, M. Caricato, X. Li, H. P. Hratchian, A. F. Izmaylov, J. Bloino, G. Zheng, J. L. Sonnenberg, M. Hada, M. Ehara, K. Toyota, R. Fukuda, J. Hasegawa, M. Ishida, T. Nakajima, Y. Honda, O. Kitao, H. Nakai, T. Vreven, J. A. Montgomery Jr., J. E. Peralta, F. Ogliaro, M. Bearpark, J. J. Heyd, E. Brothers, K. N. Kudin, V. N. Staroverov, R. Kobayashi, J. Normand, K. Raghavachari, A. Rendell, J. C. Burant, S. S. Iyengar, J. Tomasi, M. Cossi, N. Rega, J. M. Millam, M. Klene, J. E. Knox, J. B. Cross, V. Bakken, C. Adamo, J. Jaramillo, R. Gomperts, R. E. Stratmann, O. Yazyev, A. J. Austin, R. Cammi, C. Pomelli, J. W. Ochterski, R. L. Martin, K. Morokuma, V. G. Zakrzewski, G. A. Voth, P. Salvador, J. J. Dannenberg, S. Dapprich, A. D. Daniels, Ö. Farkas, J. B. Foresman, J. V. Ortiz, J. Cioslowski and D. J. Fox, Gaussian 09, Revision D.01, Gaussian, Inc., Wallingford CT, 2009.

34) R. A. Jockusch and E. R. Williams J. Phys. Chem. A 1998, 102, 4543-4550.

35) P. D. Schnier, W. D. Price, E. F. Strittmatter, and E. R. Williams J. Am. Soc. Mass Spectrom. 1997, 8, 771-780.

36) Y. Jami-Alahmadi, T. D. Fridgen Journal of Mass Spectrometry 429 (2018) 136-141.

37) M. T. Rodgers, K. M. Ervin, P. B. Armentrout, Journal of Chemical Physics 106 (1997) 4499-4508.

38) P. Bayat, D. Gatineau, D. Lesage, S. Marhabaie, A. Martinez, R. B. Cole, Investigation of hemicryptophane host-guest binding energies using high-pressure collision-induced dissociation in combination with RRKM modeling. J. Am. Soc. Mass Spectrom. 30 (2019) 509518.

39) M. Karanik, D. Lesage, Y. Gimbert, P. Nava, S. Humbel, L. Giordano, G. Buono, J.-C. Tabet, Do platinum(II) and palladium(II) phosphinito phosphinous acids generate the same type of reactive intermediate in alkyne coordination? A gas-phase study with phenylethyne and propargyl acetate. Organometallics 30 (2011) 4814-4821.

40) B. Jia, L. A. Angel and K. M. Ervin J. Phys. Chem. A 2008, 112, 1773-1782. 